\title{
Novel sonochemical green approach for synthesis of highly crystalline and thermally stable barium sulphate nanoparticles using Azadirachta indica leaf extract
}

\author{
MINAKSHI JHA, SHABNAM ANSARI and NAVINCHANDRA G SHIMPI*D \\ Department of Chemistry, University of Mumbai, Santacruz (E), Mumbai 400098, India \\ *Author for correspondence (navin_shimpi@ rediffmail.com)
}

MS received 25 December 2017; accepted 15 April 2018; published online 23 January 2019

\begin{abstract}
Nanomaterial synthesized using plant extract is a viable and better alternative to chemical synthesis methods. A simple, nontoxic and inexpensive strategy, which meets the standard of green chemistry, has been introduced for the synthesis of highly crystalline and thermally stable barium sulphate $\left(\mathrm{BaSO}_{4}\right)$ nanoparticles. This work reports ultrasonic-assisted green synthesis of $\mathrm{BaSO}_{4}$ nanoparticles using Azadirachta indica leaf extract at room temperature. The as-synthesized $\mathrm{BaSO}_{4}$ nanoparticles were subjected to various physiochemical characterization using X-ray diffraction (XRD), Fourier transform infrared spectroscopy (FTIR), field emission gun-scanning electron microscopy (FEG-SEM), thermogravimetric analysis (TGA) and energy-dispersive X-ray spectroscopy (EDX). XRD explored orthorhombic, highly crystalline and pure $\mathrm{BaSO}_{4}$ (JCPDS: 24-1035) with average crystallite size of $55.6 \mathrm{~nm}$. FEG-SEM study revealed about size $(>80 \mathrm{~nm})$ of $\mathrm{BaSO}_{4}$ nanoparticles. Co-precipitation method was also employed to synthesize $\mathrm{BaSO}_{4}$ for comparison between biogenic and chemical methods. The size of $\mathrm{BaSO}_{4}$ nanoparticles obtained using co-precipitation method was very large with rod shape morphology. Novel sonochemical green method is preferable because of its control over particle size as well as morphology. FTIR study confirmed the formation of $\mathrm{BaSO}_{4}$ nanoparticles. High thermal tolerance and stability of $\mathrm{BaSO}_{4}$ nanoparticles was evidenced from single step weight loss in TGA. In addition, strong characteristic signals of barium, sulphur and oxygen in EDX confirmed the purity of ultrasonic-assisted green synthesized $\mathrm{BaSO}_{4}$ nanoparticles. Overall, this one pot, inexpensive and green sonochemical approach is a promising method for the synthesis of $\mathrm{BaSO}_{4}$ nanoparticles, which might be used for various commercial applications.
\end{abstract}

Keywords. A. indica; $\mathrm{BaSO}_{4}$ nanoparticles; XRD; TGA; FEG-SEM.

\section{Introduction}

Recently, synthesis of efficient nanomaterials with colossal applications is emerging and crucial to meet increasing demand for advanced materials. Fabrication of industrially important materials has rapidly developed into a promising field in materials science. The prospect of commercial application has drastically accelerated the growing demand of multifunctional barium sulphate $\left(\mathrm{BaSO}_{4}\right)$ nanoparticles. $\mathrm{BaSO}_{4}$ is important in various applications such as catalyst carrier, adsorbent materials, biomedical devices, engineering plastics and so on [1-3]. Due to its ability to increase the density of fluid and hydrostatic pressure of a well it reduces blowout and applied as a drilling fluid in off-shore oil production [4]. The white transparent colour of $\mathrm{BaSO}_{4}$ is extensively applied in white pigment, printing ink and cosmetics. A high burning point and water insoluble nature makes it suitable as a coating material and is mostly used in paper brighteners. Its opaque nature towards $\mathrm{X}$-rays is useful in medical imaging to visualize the intestinal tract. Hence it is recommended to drink a cocktail containing $\mathrm{BaSO}_{4}$ and its progress through digestive organs can be scanned by $\mathrm{X}$-rays. Furthermore, it is used as a filler to enhance density and used in root-canal filling, plastic, paint and rubber industry. Other applications include soil testing (soil pH), as a catalyst support (Rosenmund reduction), in pyrotechnics, in colorimetry, in glass, TV screens, car filters, ceramics and electronics. Bhide et al have investigated photoluminescence properties of $\mathrm{U}_{6}{ }^{+}$doped $\mathrm{BaSO}_{4}$ [5]. Esen et al have studied the $\mathrm{X}$-rays and radioisotope energy absorption capacity of heavyweight concrete containing barite aggregate [6]. Practically, synthesis of $\mathrm{BaSO}_{4}$ is beneficial for lots of commercial applications.

Various researchers have reported a number of synthetic strategies such as precipitation [7-9], microemulsion [10], organic modification [11], membrane separation [12] for $\mathrm{BaSO}_{4}$ fabrication. Bala et al have synthesized $\mathrm{BaSO}_{4}$ through a precipitation reaction using octadecyl dihydrogen phosphate (ODP; $n-\mathrm{C}_{18} \mathrm{H}_{37} \mathrm{OPO}_{3} \mathrm{H}_{2}$ ) as a modifier. 
Sun et al have also synthesized $\mathrm{BaSO}_{4}$ nanoparticles in the presence of sodium polyacrylate by simple precipitation [13]. Adityawarman synthesized $\mathrm{BaSO}_{4}$ nanoparticles via a non-ionic microemulsion synthetic method [14], Gupta used sodium hexametaphosphate as a stabilizer to obtain $\mathrm{BaSO}_{4}$ nanoparticles [7]. Some other approaches used for $\mathrm{BaSO}_{4}$ synthesis include microchannel reactor [15], two phase flow microreactor [16], membrane microreactor [17], rotating liquid film reactor [18], spinning disc reactor [19] and T-mixture reactor [20]. These methods for $\mathrm{BaSO}_{4}$ fabrication are expensive and energy intensive and inflict environment risk by using noxious and persistent reagents. To overcome these problems, new emerging nanotechnology, green nanotechnology provides an eco-friendly and cost-effective solution by utilizing plant extract as a reducing and stabilizing agent without consuming or generating toxic chemicals and its by-products [21-24]. Previously, our research group synthesized various nanomaterials $\left(\mathrm{ZnO}, n-\mathrm{BaCO}_{3}, \mathrm{CaCO}_{3}, \mathrm{CaSO}_{4}, \mathrm{TiO}_{2}\right.$, AgNPs and $\left.\mathrm{Mg}(\mathrm{OH})_{2}\right)$ using chemical as well as bio-inspired green methods [25-33].

Present work reports reliable, bioinspired, eco-friendly green sonochemical route for $\mathrm{BaSO}_{4}$ synthesis using Azadirachta indica leaf extract (A. indica LE), which works as a bioreducing, capping and stabilizing agent. Synergic coupling of sonochemistry and green chemistry protocol contributes to innovative and attractive advances in terms of low-cost, non-toxic processing, high reaction rate, less time and energy consuming, controlled size and morphology etc. A. indica is also known as neem tree (figure 1). Taxonomic classification of $A$. indica is provided as - Kingdom, Order: Plantae, Sapindales; Family, subfamily: Meliaceae, Melioiae; Tribe, Genus, species: Melieae, Azadirachta, A. indica.

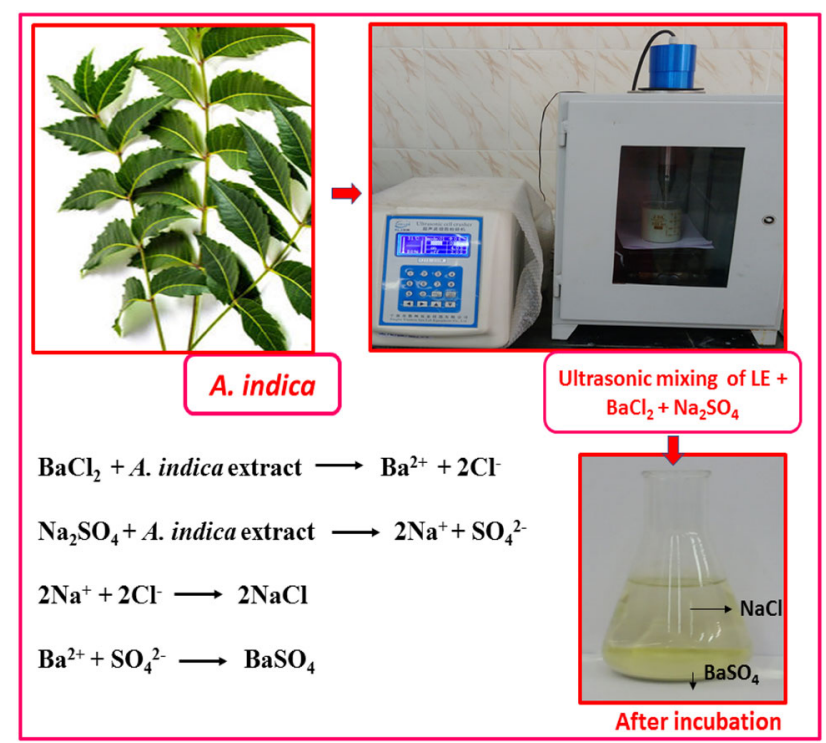

Figure 1. Schematic representation of synthetic procedure followed during ultrasonic-assisted green synthesis of $\mathrm{BaSO}_{4}$ with probable mechanistic path.
This is generally grown in tropical and semi-tropical regions. Phytocomponents of $A$. indica leaf extract includes alkaloids, flavonoids, reducing sugar, tannin, saponin, triterpenoid, carbohydrates and protein. As per the literature data available, this is the first ever report on ultrasonicassisted green synthesis of $\mathrm{BaSO}_{4}$ using $A$. indica LE. This report is significant for bioinspired low-cost protocol for multifunctional inorganic $\left(\mathrm{BaSO}_{4}\right)$ nanomaterial development. The novelty of proposed synthesis lies predominantly in its simplicity of the experimental process (without inert conditions, high temperature, pressure, surfactant and is less time consuming). Development of novel synthetic strategy using efficient green precursor and non-toxic solvent as well as rapid, one-pot, less energy intensive synthesis, could provide significant environmental and economic advantages. This paper unveils a green approach designed for the synthesis of $\mathrm{BaSO}_{4}$ and its physiochemical properties have been investigated.

\section{Experimental}

\subsection{Chemicals and characterization}

Anhydrous sodium sulphate $\left(\mathrm{Na}_{2} \mathrm{SO}_{4}\right)$ and barium chloride dihydrate $\left(\mathrm{BaCl}_{2} \cdot 2 \mathrm{H}_{2} \mathrm{O}\right)$ were procured from S. D. FineChem Limited, Mumbai (India). Cetyltrimethylammonium bromide (CTAB, $\mathrm{C}_{19} \mathrm{H}_{42} \mathrm{BrN}$, 99\%, Fluka) was used as a stabilizer without further purification. Ethanol and deionized water were used throughout the experimentation. A. indica fresh leaves were collected from University campus, Kalina, Mumbai. Glassware was thoroughly washed using aqua regia and rinsed using distilled water and acetone, prior to synthesis.

Ultrasonic cell with processor (SJIA-250 W) (Unigenetics Instruments, New Delhi) was used for the synthesis of $\mathrm{BaSO}_{4}$ nanoparticles. Fourier transform infrared spectroscopy (FTIR) was performed on Perkin-Elmer Frontier, Private Limited (India) in the range of $4000-400 \mathrm{~cm}^{-1}$ at a resolution of $4 \mathrm{~cm}^{-1}$ to identify functional groups present in A. indica $\mathrm{LE}$ and $\mathrm{BaSO}_{4}$. Crystalline nature and crystallographic phase were identified using X-ray diffractogram Shimadzu XRD 7000 with operating voltage $40 \mathrm{kV}, \mathrm{CuK} \alpha$ radiation $(\lambda=1.54060 \AA)$, current $30 \mathrm{~mA}$ and scan range $15-80^{\circ}$, count time $0.60 \mathrm{~s}$. Diffraction peaks of crystalline phases were compared with standard JCPDS data. Thermal stability and weight loss of $\mathrm{BaSO}_{4}$ were studied on a thermal gravimetric analyser at $30-1000^{\circ} \mathrm{C}$. The sample was kept in an aluminium pan sample holder and exposed to heating under continuous nitrogen purging $\left(20 \mathrm{ml} \mathrm{min}^{-1}\right)$. SEM was performed on JEOL JSM-7600F (USA) combined with energy-dispersive X-ray (EDX) spectroscopy to study the size, shape and elemental composition of $\mathrm{BaSO}_{4}$ nanoparticles. SEM imaging was performed with an accelerating voltage of $15 \mathrm{kV}$. Platinum sputtering was applied before SEM imaging. 


\subsection{Extract preparation and synthesis of $\mathrm{BaSO}_{4}$}

Fresh leaves of $A$. indica were washed several times with double distilled water along with deionized water to remove contaminants from the surface and shade dried at room temperature. After 7 days, the dried leaves were crushed in a grinder. Thirty gram of fine A. indica powder was added in $300 \mathrm{ml}$ of water-ethanol mixture and refluxed at $30^{\circ} \mathrm{C}$ for 60 min. After cooling, the leaf extract was filtered through Whatman filter paper and cooled for $30 \mathrm{~min}$. Further, $20 \mathrm{ml}$ of filtrate was taken in an ultrasonic probe sonicator and 40 $\mathrm{ml}$ of $0.05 \mathrm{~mol}^{-1} \mathrm{BaCl}_{2}$ solution was added dropwise during sonication. After $5 \mathrm{~min}$, with continuous sonication $40 \mathrm{ml}$ of $0.05 \mathrm{moll}^{-1} \mathrm{Na}_{2} \mathrm{SO}_{4}$ was added dropwise and a white precipitate was obtained. The reaction mixture was incubated at

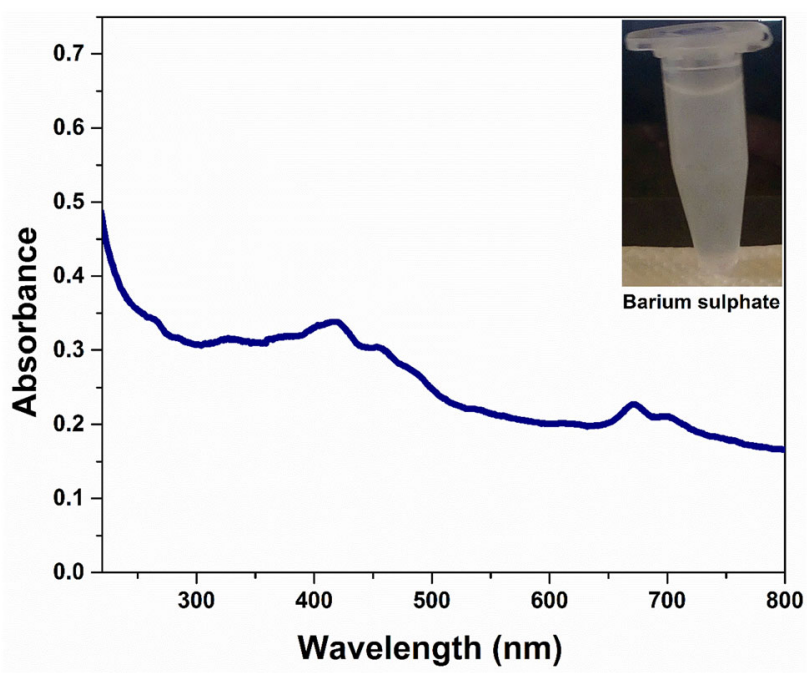

Figure 2. UV-Vis absorbance spectra of $\mathrm{BaSO}_{4}$ nanoparticles.

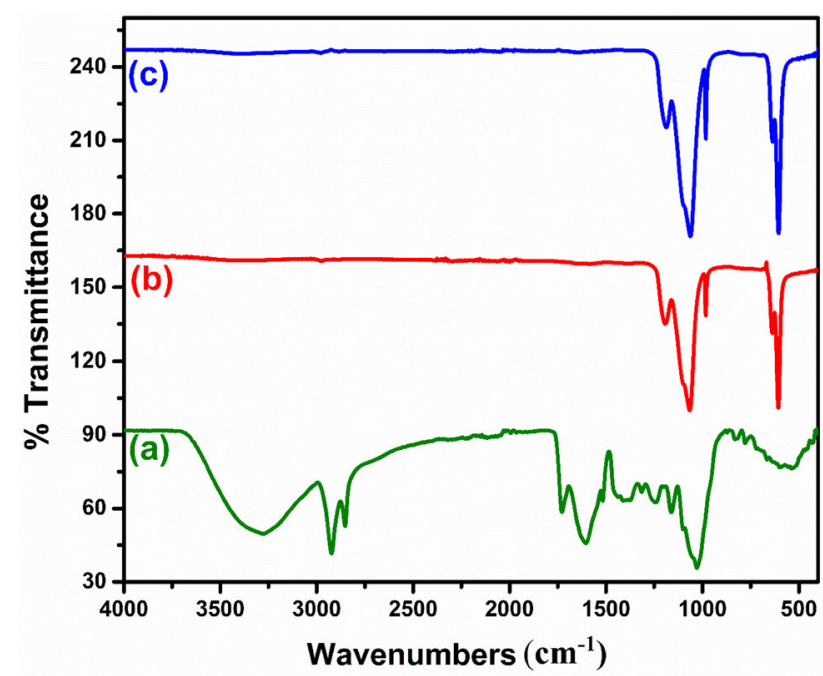

Figure 3. FTIR spectrum of (a) A. indica LE, (b) green synthesized $\mathrm{BaSO}_{4}$ and (c) chemically synthesized $\mathrm{BaSO}_{4}$. $37^{\circ} \mathrm{C}$ for $24 \mathrm{~h}$ for complete growth of $\mathrm{BaSO}_{4}$ nanoparticles. Afterwards, the white precipitate was separated by centrifugation (6000 rpm, $25 \mathrm{~min}$ ) and washed thrice with deionized water and ethanol. The obtained precipitate was vacuum dried to obtain a final mass of $\mathrm{BaSO}_{4}$. In another experiment, $\mathrm{BaSO}_{4}$ was synthesized using a co-precipitation technique in the presence of CTAB as a surfactant. The intention behind using a co-precipitation method for $\mathrm{BaSO}_{4}$ synthesis was for a comparative study of size and shape, with that obtained using the ultrasonic-assisted green method.

\section{Results and discussion}

\subsection{Mechanistic path of $\mathrm{BaSO}_{4}$ nanoparticle synthesis using ultrasonic-assisted green method}

Synthesis of $\mathrm{BaSO}_{4}$ followed green synthetic approach coupled with ultrasonic-assisted mixing of reagents $\mathrm{BaCl}_{2}$ and $\mathrm{Na}_{2} \mathrm{SO}_{4}$ and $A$. indica LE. Proposed mechanistic aspects can be explained in the following terms. Initially both $\mathrm{BaCl}_{2}$ and $\mathrm{Na}_{2} \mathrm{SO}_{4}$ get reduced and then the reaction of barium ions $\left(\mathrm{Ba}^{2+}\right)$ and sulphate ions $\left(\mathrm{SO}_{4}{ }^{2-}\right)$ generates $\mathrm{BaSO}_{4}$


Figure 4. (a) X-ray diffractogram of $\mathrm{BaSO}_{4}$ synthesized using A. indica LE (JCPDS card no. 241035). (b) XRD of crystalline $\mathrm{BaSO}_{4}$ nanoparticles synthesized using chemical co-precipitation method. 
precipitate in the reaction mixture. As $\mathrm{BaSO}_{4}$ is insoluble in water, its precipitate settles at the bottom and $\mathrm{NaCl}$ remains in the solvent mixture. Figure 1 shows the mechanistic path of nanoparticle synthesis. Probably in reaction mixture, $\mathrm{Ba}^{2+}$ makes a complex with phytocomponents and after that the entrapped $\mathrm{Ba}^{2+}$ reacts with $\mathrm{SO}_{4}{ }^{2-}$ generating $\mathrm{BaSO}_{4}$. Here phytocomponents of the leaf extract act as a nucleator and growth modifier. Some consequent secondary processes such as capping, ageing, agglomeration, ripening and breakage might occur depending upon the nature of interaction of phytocomponents and the reaction process. Mostly, the nucleation rate is governed by temperature, degree of supersaturation, phytocomponent encapsulation and surface energy. Size control is governed by these factors to a large extent. Increment in supersaturation decreases surface energy and consequently increases nucleation rate which leads ultimately to small sized nanoparticles. Moreover, the exact phenomenon involved in ultrasonication is acoustic cavitation which produces high energy shock waves and increases nucleation rate and a simultaneous collapse of

Table 1. Details of diffraction pattern, $d$-spacing, lattice strain, crystallite size and average size of $\mathrm{BaSO}_{4}$ nanoparticles.

\begin{tabular}{lllcccc}
\hline $2 \theta\left(^{\circ}\right)$ & $d(\AA)$ & $h k l$ & $\operatorname{FWHM}(\beta)$ & Lattice strain & Crystallite size $(\mathrm{nm})$ & Average size $(\mathrm{nm})$ \\
\hline 20.45 & 4.3386 & 101 & 0.14670 & 0.0035 & 57.5 & 55.6 \\
22.79 & 3.8978 & 111 & 0.14200 & 0.0031 & 59.62 & \\
25.84 & 3.4443 & 021 & 0.14930 & 0.0028 & 57.04 & \\
28.74 & 3.1031 & 121 & 0.14790 & 0.0025 & 57.94 & \\
31.53 & 2.8345 & 211 & 0.17030 & 0.0026 & 50.63 \\
32.78 & 2.7291 & 002 & 0.18800 & 0.0028 & 46.01 & \\
36.17 & 2.4813 & 221 & 0.13310 & 0.0018 & 65.61 & \\
38.73 & 2.3228 & 022 & 0.18170 & 0.0023 & 48.42 \\
40.79 & 2.2102 & 122 & 0.15500 & 0.0018 & 57.14 & \\
42.59 & 2.1206 & 140 & 0.15220 & 0.0017 & 58.54 & \\
44.00 & 2.0559 & 041 & 0.16560 & 0.0018 & 54.06 & \\
\hline
\end{tabular}



Figure 5. TGA thermogram of $\mathrm{BaSO}_{4}$ synthesized using A. indica LE. 


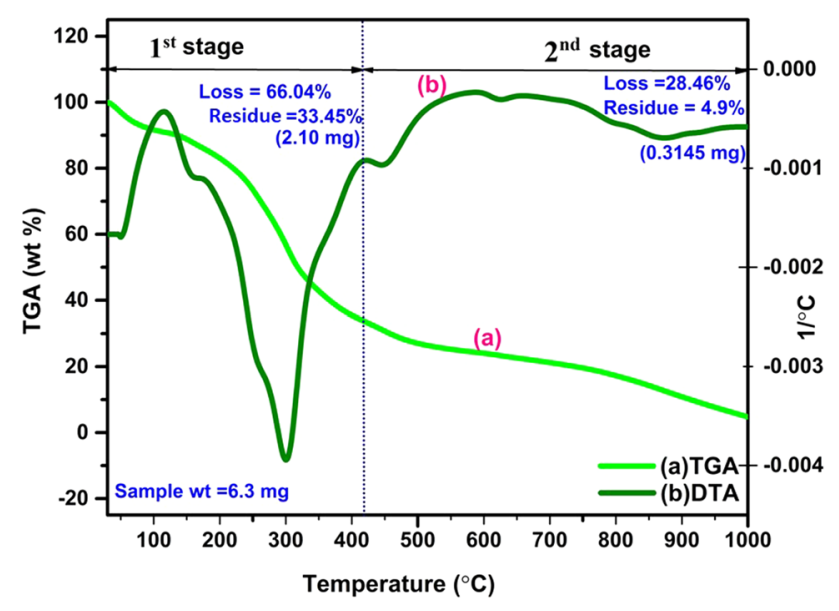

Figure 6. (a) TGA thermogram of A. indica LE and (b) supporting derivative curve. fast bubble turn out a high rate of temperature decrease which stops agglomeration and organization of particles, leading to small size nano-crystal formulation. Figure 2 shows the absorbance of $\mathrm{BaSO}_{4}$ nanoparticle in the UV-Vis spectrum. The result confirms the purity of the as-synthesized nanoparticles.

\subsection{FTIR analysis}

Figure 3 a shows the functional group of reducing and stabilizing agents available in A. indica LE. Band at $3278 \mathrm{~cm}^{-1}$ depicts intermolecular bonded $-\mathrm{OH}$ group (polyphenol or flavonoid). Observed transmittance peaks at 2921 and $2852 \mathrm{~cm}^{-1}$ correspond to alkane group. Band at 1725 and 1602 can be assigned to aromatic $\mathrm{C}=\mathrm{O}$ and $\mathrm{C}=\mathrm{C}$ stretchings. Band at $1163 \mathrm{~cm}^{-1}$ represents tertiary alcohol and
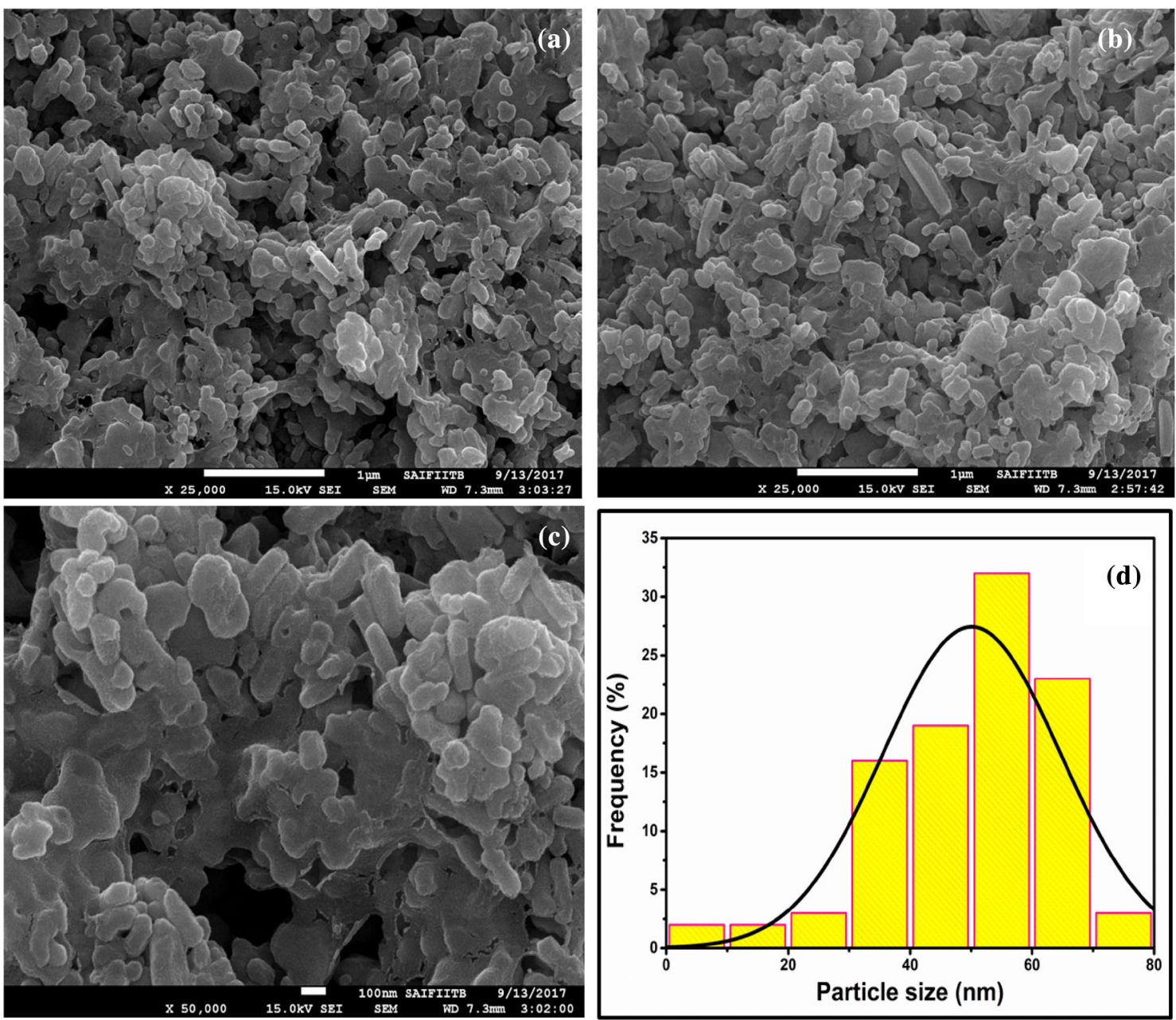

Figure 7. FEG-SEM of $\mathrm{BaSO}_{4}$ nanoparticle synthesized using A. indica (under magnification of $1 \mu \mathrm{m}(\mathbf{a}, \mathbf{b})$ and $100 \mathrm{~nm}(\mathbf{c}))$. The frequency (\%) vs. particle size histogram corresponding to (c) is presented in (d) showing nanoparticles $>80 \mathrm{~nm}$. 
$1024 \mathrm{~cm}^{-1}$ displays anhydride. These functional groups are actively involved in reduction, capping and stabilization. From the graph it appears that vibrational group at $3278 \mathrm{~cm}^{-1}$ is very much shifted (completely participated) and actively involved in the reduction of $\mathrm{Na}_{2} \mathrm{SO}_{4}$ and $\mathrm{BaCl}_{2}$ in the prepared sample.

Figure 3 b represents the FTIR spectra of ultrasonic-assisted green synthesized $\mathrm{BaSO}_{4}$. Characteristic transmittance peaks at 1192,1064 and $980 \mathrm{~cm}^{-1}$ correspond to symmetric vibrational stretching of $\mathrm{SO}_{4}{ }^{2-}$, whereas a peak at $604 \mathrm{~cm}^{-1}$ is attributed to out-of-plane bending of sulphate $\left(\mathrm{SO}_{4}{ }^{2-}\right)$ group [34]. According to Alder and Kerr, sulphur-oxygen (S-O) stretching of inorganic sulphate is found in the characteristic region of $1192-1072 \mathrm{~cm}^{-1}$ [35]. FTIR results are in complete agreement with successful formation of $\mathrm{BaSO}_{4}$ using A. indica LE. Figure 3c demonstrates FTIR of $\mathrm{BaSO}_{4}$
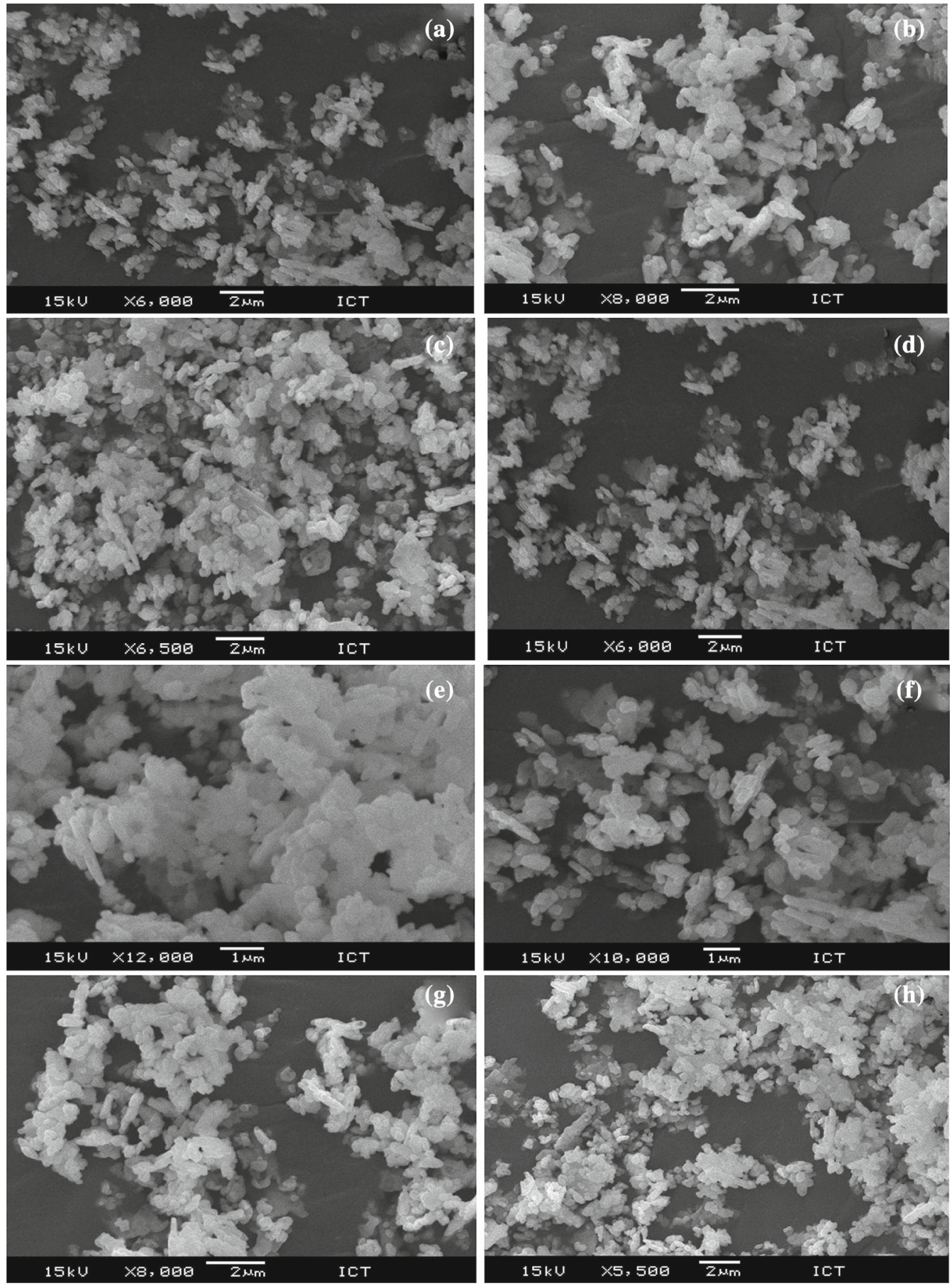

Figure 8. FEG-SEM images of powdered $\mathrm{BaSO}_{4}$ (without sonication) synthesized using chemical route under different magnifications $(\mathbf{a}-\mathbf{h})$. 
synthesized using the co-precipitation method. Peaks were completely tuned with each other and confirmed the purity of synthesized $\mathrm{BaSO}_{4}$.

\subsection{X-ray diffraction (XRD) study}

Microstructural characteristics of cryo ground $\mathrm{BaSO}_{4}$ nanoparticles were investigated using XRD pattern (figure 4a). A sharp and intense diffraction peak reveals the highly crystalline nature of $\mathrm{BaSO}_{4}$ synthesized using A. indica LE. The absence of impurity peaks confirms high purity of the as-synthesized $\mathrm{BaSO}_{4}$. Reflection planes were completely matched with standard JCPDS card no. 24-1035 (see Supporting information) having a typical orthorhombic structure of $\mathrm{BaSO}_{4}$. The average crystallite size was calculated by applying Debye Scherrer equation [36]:

$$
d=\frac{K \lambda}{\beta \cos \theta},
$$

where $d$ represents crystallite size in nanometre, $K$ is Scherrer constant (0.94), $\lambda$ is the wavelength of $\mathrm{CuK} \alpha$ radiation with a value $0.154 \mathrm{~nm}, \beta$ is full width at half maximum (FWHM) in radian and $\theta$ is Bragg diffraction angle.

By using above data, the crystallite size from eleven prominent peaks was calculated and their average crystallite size was found to be $55.6 \mathrm{~nm}$ (table 1). Figure $4 \mathrm{~b}$ presents the XRD pattern of freshly prepared $\mathrm{BaSO}_{4}$ using the chemical co-precipitation technique. The diffraction pattern was found to be more intense with a crystalline nature. The average crystallite size was found to be $\sim 98.12 \mathrm{~nm}$. The results indicate that ultrasonic-assisted green method provides good control over size as compared to the chemical co-precipitation method.

\subsection{Thermogravimetric and differential thermal analysis}

Figure 5 presents thermogravimetric analysis (TGA) of $\mathrm{BaSO}_{4}$ nanoparticles exhibiting high thermal stability. Organic decomposition at temperature $310^{\circ} \mathrm{C}$ was observed from derivative weight loss curve, which corresponds to mass loss of $7.69 \%$, this behaviour was most likely a consequence of the surface desorption of the bio-organic compounds present in A. indica LE getting involved in capping of $\mathrm{BaSO}_{4}$. Single weight loss in TG thermogram, single derivative formation in derivative weight loss curve and $92.30 \%$ residue of pure $\mathrm{BaSO}_{4}$ strongly evidences high thermal stability of $\mathrm{BaSO}_{4}$ nanoparticle synthesized using $A$. indica $L E$. Figure $6 \mathrm{a}$ and $b$ shows TGA and derivative curve of $A$. indica LE, where only $4.9 \%$ residue remained after two successive weight losses (66.04 and $28.46 \%$ ), which was observed as a consequence of surface desorption of bio-organic moiety acted as reducing and stabilizing agent during synthesis of $\mathrm{BaSO}_{4}$.

\subsection{Morphological study}

Figure 7 displays the field emission gun-scanning electron microscopy (FEG-SEM) images of $\mathrm{BaSO}_{4}$. Figure $7 \mathrm{a}$ and b displays FEG-SEM under magnification of $1 \mu \mathrm{m}$, while figure 7c presents nanoparticles on a $100 \mathrm{~nm}$ magnification scale. Figure $7 d$ presents the frequency $(\%) v s$. particle size distribution diagram. Result reveals the influence of $A$. indica $\mathrm{LE}$ on the morphology of $\mathrm{BaSO}_{4}$. FEG-SEM reveals rod-like $\mathrm{BaSO}_{4}$ nanoparticles with size $>80 \mathrm{~nm}$. Previous reports have shown larger particle size of $\mathrm{BaSO}_{4}$ synthesized using chemical route. Hopwood and Mann have reported synthesis of $\mathrm{BaSO}_{4}$ in DDAB microemulsion and



Figure 9. EDX spectra of $\mathrm{BaSO}_{4}$ with characteristic signals of $\mathrm{Ba}, \mathrm{S}$ and $\mathrm{O}$. 
nanoparticles were of $200 \mathrm{~nm}$ in size [37]. Liu and $\mathrm{Wu}$ reported biomimetically synthesized $\mathrm{BaSO}_{4}$ nanotubes with length $1.5-2.5 \mu \mathrm{m}$. According to the report, synthesized nanotubes had an external diameter and inner diameter with size range 90-140 and 73-122 nm, respectively [38]. Cofiero et al had synthesized $\mathrm{BaSO}_{4}$ using a spinning disc reactor and found nanoparticles in size range 3-0.7 $\mu \mathrm{m}$ [39]. Sun et al reported PAAS modified $\mathrm{BaSO}_{4}$ in the size range of 100-300 nm diameter [13]. In this report also, $\mathrm{BaSO}_{4}$ synthesized using chemical method (co-precipitation technique) showed a large particle size $(\sim 80-600 \mathrm{~nm})$ under magnification of 1 and $2 \mu \mathrm{m}$ scale in SEM analysis. The SEM images were taken without ultrasonication. Figure $8 \mathrm{a}-\mathrm{h}$ displays morphology of chemically synthesized $\mathrm{BaSO}_{4}$ which is rod shaped hierarchical architectures with some agglomeration. Overall, A. indica green LE has proved to be an efficient size controller and ultrasonic-assisted green method provided small sized $\mathrm{BaSO}_{4}$ nanoparticles for several commercial applications.

\subsection{EDX analysis}

To further study the chemical composition and purity of assynthesized $\mathrm{BaSO}_{4}, \mathrm{EDX}$ measurement was performed. $\mathrm{EDX}$ study of $\mathrm{BaSO}_{4}$ explored the strong signal of $\mathrm{Ba}, \mathrm{S}$ and $\mathrm{O}$. The inset represents the area selected for elemental mapping of present elements (figure 9). All characteristic signals reveal that sample possess $\mathrm{Ba}, \mathrm{S}$ and $\mathrm{O}$ elements only. Another less intense signal appeared due to platinum coating during SEM analysis. The weight percentage of elements in the sample was $60.81 \% \mathrm{Ba}, 14.47 \% \mathrm{~S}$ and $21.71 \% \mathrm{O}$. The weight of elements in EDX confirms that sample contains $\mathrm{BaSO}_{4}$ nanoparticles.

\section{Conclusion}

The present work reports a sustainable, less energy intensive, novel and rapid synthetic technique for the synthesis of stable and size controlled $\mathrm{BaSO}_{4}$ nanoparticles using A. indica LE. The synthesis was conducted without any additive or surfactant. Green protocol facilitates to obtain highly pure, orthorhombic, crystalline and thermally stable $\mathrm{BaSO}_{4}$ nanoparticles. XRD revealed high purity and crystalline nature of the as-synthesized $\mathrm{BaSO}_{4}$ with average crystallite size $55.6 \mathrm{~nm}$. FEG-SEM images confirmed about rod morphology with particle size range $>80 \mathrm{~nm}$. The presence of vibrational stretching of $\mathrm{SO}_{4}^{2-}$ group in FTIR confirmed the formation of $\mathrm{BaSO}_{4}$ nanoparticles without any surfactant or stabilizer. High consistency in elemental presence was confirmed by EDX analysis which explored the presence of characteristic strong signals of $\mathrm{Ba}, \mathrm{S}$ and $\mathrm{O}$ elements. TGA study strongly evidenced the high thermal stability of $\mathrm{BaSO}_{4}$ nanoparticles, it was completely stable up to $310^{\circ} \mathrm{C}$ and a single weight loss of $7.69 \%$ was observed with $92.30 \%$ residue. The above results strongly confirmed the formation of the thermally stable and highly crystalline $\mathrm{BaSO}_{4}$ nanoparticles using this novel ultrasonic-assisted green synthetic approach. This green synthetic approach may be extended to other noble material synthesis. Sustainable non-toxic biocompatible precursor of green methodology provided reduced particle size of $\mathrm{BaSO}_{4}$ as compared to previously reported and chemically synthesized method. Small sized nanoparticles can be employed for possible pharmaceutical applications as a potential contrast agent for X-ray examinations without any side effects. In addition, physiochemical properties such as excellent stability, inertness, whiteness, high specific gravity and outstanding optical property makes it suitable for various industrial, medicinal and technological applications.

\section{Acknowledgements}

One of the authors (M Jha) is thankful to the University Grants Commission (UGC), New Delhi (India) for financial support to carry out this work. Authors are also thankful to SAIF, IIT Mumbai and Microanalytical Laboratory, Department of Chemistry, University of Mumbai, Mumbai for providing characterization facilities.

\section{References}

[1] Fang C, Hou R, Zhou K, Hua F, Cong Y, Zhang J et al 2014 J. Mater. Chem. B 91264

[2] Wang K, Wu J, Ye L and Zeng H 2003 Compos. Part A Appl. Sci. Manuf. 341199

[3] Ramaswamy V, Vimalathithan R M, Ponnusamy V and Jose M T 2013 J. Lumin. 134791

[4] Bakke T, Klungsoyr J and Sanni S 2013 Mar. Environ. Res. 92 154

[5] Bhide M K, Seshagiri T K, Ojha S and Godbole S V 2014 Bull. Mater. Sci. 37123

[6] Esen Y and Yilmazer B 2011 Bull. Mater. Sci. 34169

[7] Gupta A, Singh P and Shivakumara C 2010 Solid State Commun. 150386

[8] Saraya E S I and Bakr I M 2011 Am. J. Nanotechnol. 2106

[9] Bala H, Fu W, Guo Y, Zhao J, Jiyang Y, Ding X et al 2006 Colloids Surf. A Physicochem. Eng. Asp. 27471

[10] Qi L, Ma J, Cheng H and Zhao Z 1996 Colloids Surf. A Physicochem. Eng. Asp. 108117

[11] Shen Y, Li C, Zhu X, Xie A, Qiu L and Zhu J 2007 J. Chem. Sci. 119319

[12] Wu G, Zhou H and Zhu S 2007 Mater. Lett. 61168

[13] Sun Y, Zhang F, Wu D and Zhu H 2014 Particuology 1433

[14] Adityawarman D, Voigt A, Veit P and Sundmacher K 2016 MATEC Web Conf. 6702017

[15] Wang Q A, Wang J X, Li M, Shao L and Chen J F 2009 Chem. Eng. J. 149473478

[16] Jeevarathinam D, Gupta A K, Pitchumani B and Mohan R 2011 Chem. Eng. J. 173607

[17] Chen G, Luo G S, Xu J H and Wang J D 2004 Powder Technol. 139180

[18] Guo S C, Evans D G, Li D Q and Duan X 2009 AlChE J. 55 2024 
[19] Dehkordi A M and Vafaeimanesh A 2009 Ind. Eng. Chem. Res. 487574

[20] Schwarzer H C and Peukert W 2002 Chem. Eng. Technol. 25 657

[21] Joseph S and Mathew B 2015 Bull. Mater. Sci. 38659

[22] Sutradhar P and Saha M 2015 Bull. Mater. Sci. 38653

[23] Vinmathi V and Jacob S J P 2015 Bull. Mater. Sci. 38 625

[24] Devi H S, Singh T D and Singh H P 2017 Bull. Mater. Sci. 40 163

[25] Shimpi N G, Jain S, Karmakar N, Shah A, Kothari D C and Mishra S 2016 Appl. Surf. Sci. 39017

[26] Jain S, Karmakar N, Shah A, Kothari D C, Mishra S and Shimpi N G 2017 Appl. Surf. Sci. 3961317

[27] Mishra S, Shimpi N G and Patil U D 2007 J. Polym. Res. 14 449

[28] Mishra S and Shimpi N G 2007 J. Appl. Polym. Sci. 104 2018
[29] Shimpi N G, Mali A D, Hansora D P and Mishra S 2015 Nanosci. Nanoeng. 38

[30] Ghanshyam B, Sonawane S S, Kailas L W, Ajit P R, Shirish H S and Shimpi N G 2017 Res. J. Chem. Environ. 2139

[31] Shimpi N G, Verma J and Mishra S 2009 Polym. Plast. Technol. Eng. 48297

[32] Shimpi N G, Shirole S, Suryawanshi Y and Mishra S 2017 Adv. Polym. Technol. 36160

[33] Jha M and Shimpi N G 2018 J. Genet. Eng. Biotechnol. 16115

[34] Ramaswamy V, Vimalathithan R M and Ponnusamy V 2010 Adv. Appl. Sci. Res. 1197

[35] Alder H H and Kerr P F 1965 Am. Miner. 50132

[36] Shimpi N G and Jha M 2017 IJPSR 85100

[37] Hopwood J D and Mann S 1997 Chem. Mater. 91819

[38] Liu J K, Wu Q S, Ding Y P and Wang S Y 2004 J. Mater. Res. 192803

[39] Cafiero L M, Baffi G, Chianese A and Jachuck R J J 2002 Ind. Eng. Chem. Res. 415240 